\title{
2002 British and Irish Dental Associations' Annual Conference
}

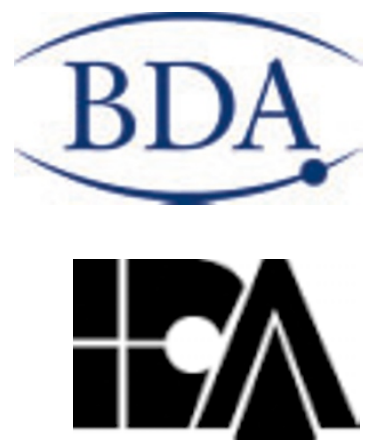

\section{Elinor Parker}

This year's annual conference held at Belfast's Waterfront Hall proved a

resounding success. The three-day conference focused on 'Quality

Partnership' - the importance of the dentist/team partnership, keeping-

up-to-date and ensuring patients are well informed.

You have to admire their courage. With the title 'Holes in your pockets' already assigned to a periodontal session, the GDC faced the profession at the BDA conference in Belfast under the more anodyne heading, 'Meet the GDC'. As expected, questions largely centred on the forthcoming increase in the retention fee. Professor Nairn Wilson and his CEO Antony Townsend rehearsed the reasons for the current deficit situation and rate rise. Drs Alex and Dan Mehigan, who have a large practice in South London, described the audience as "resigned and frustrated". Questions also addressed the themes of loss of self-regulation, unfair multiple fees for specialists, lack of a non-practicing concession, reductions in service levels and doubts about efficiency. The information from the speakers that "Massive amounts of money are being spent on a very few

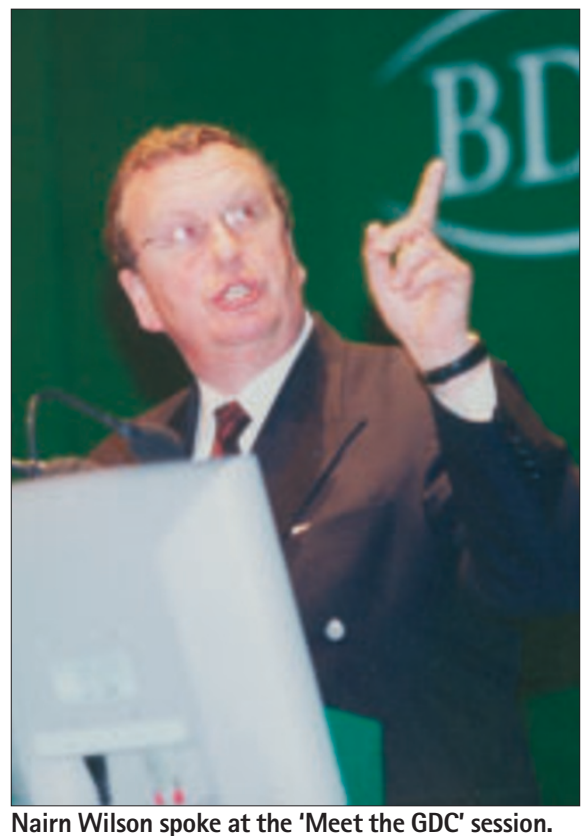

Nairn Wilson spoke at the 'Meet the GDC' session.

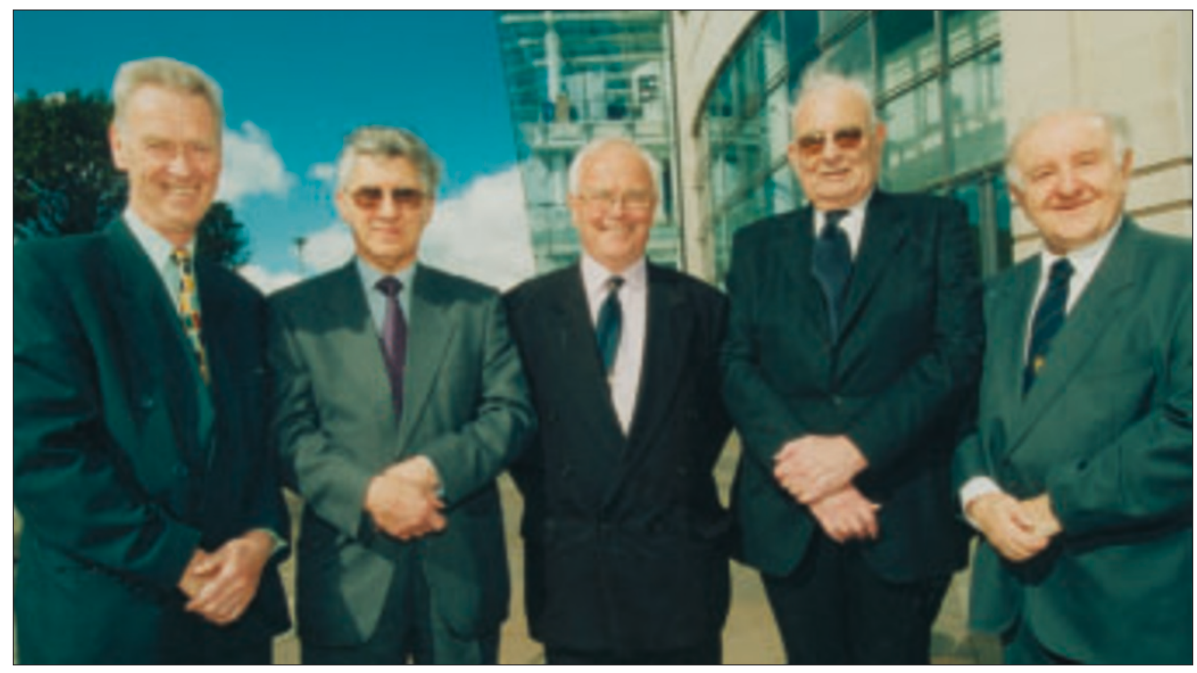

Pictured from left to right: Philip Jenkins, Tony Hudson, Geoffrey Garnet, John Bulman and Stanley Gelbier were all recognised for their achievements at the BDA Presidential Meeting.

dentists" may herald a system in future of New in ...' to help keep specialists abreast of attempting to recover costs from those found to be at fault. Has anyone suggested the Office of Fair Trading looks at lawyers fees? Are they charging six times what they get on Legal Aid?

Perhaps the attention span of the average dentist is going down, or maybe 'Hot Tips' in 15 minute bites are the most effective way of updating. Once again it was standing room only for this year's rapidfire succession of topics ranging from instant implants, homeopathy, crown and bridge, marketing, audit, anterior composites and oral medicine. It certainly concentrates the mind of the speaker and avoided the longeurs of some of the main sessions where routine clinical details were rehearsed ad nauseam. Some participants suggested that next year the session should be in the main auditorium, displacing longer single topic lectures to the smaller venues. An orthodontist suggested to me that it would be helpful to have 'What's recent advances in fields other than their own, especially where disciplines connect.

After hearing the celebrated Bernard Touati go through the same details of tooth preparation, fabrication, use of a capsule mixing machine, aesthetics, hybridisation and cementation of ceramic restorations for many similar cases I could forgive the man quietly snoring three rows in front. Wakened gently by Professor Bernard

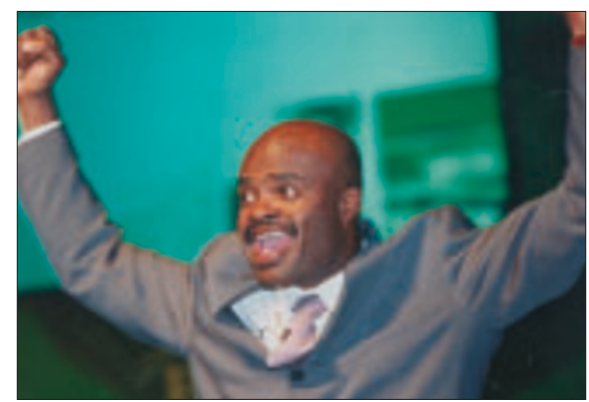

Kriss Akabusi helps the conference get off with a bang! 


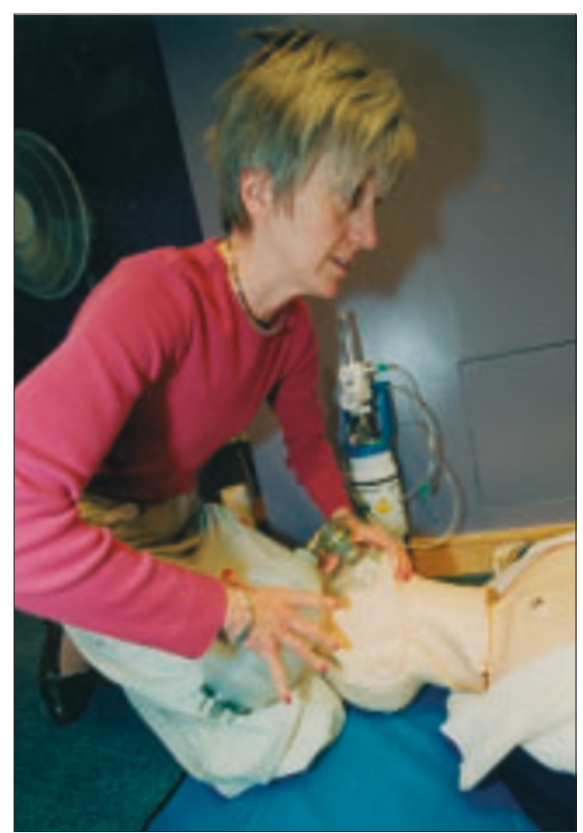

A demonstration of patient resuscitation at the SAAD stand.

Smith he was able to hear it all again anyway. Dr Touati showed some stunning results, particularly in perfect matching of all-ceramic restorations on blackened teeth with metal posts and adjacent vital ones. Multiple clinical and laboratory stages were needed to achieve these results, but no indication of costs or fees were given. His audience was treated to a very Gallic attitude to aesthetics in which women's upper lateral incisors must be small and their centrals 'dominant', but such wonderful photographs of beautiful women could only have been put up by an academic from France.

The attraction of the conference is surely the range of topics covered and the opportunity to choose and change the level of one's study. Some delegates were more visible at the social and tourist events than the scientific ones, but no doubt were discussing good practice all the while. For those who wanted exposure to research done with humanity and devotion

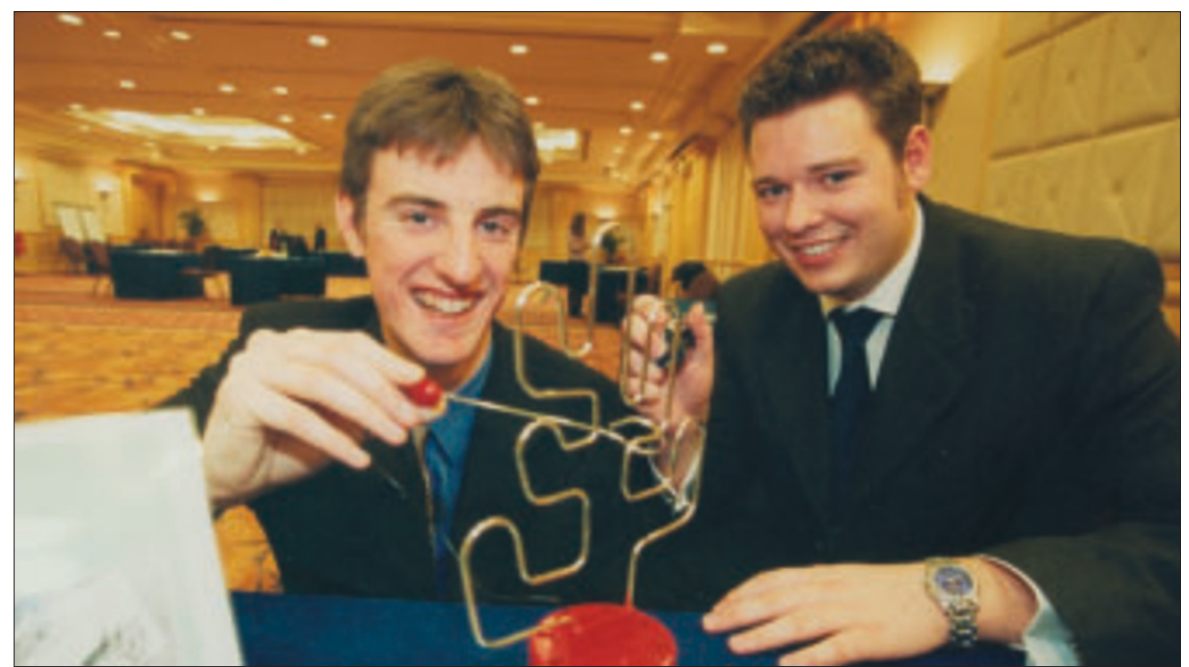

Students have a go at the wire and buzzer puzzle on BDA/Dentsply Clinician Adjudication day (1 May 2002). to detail, the 'Scar Wars' presentation by Professor Mark Ferguson of Manchester University and Renovo Limited was exemplary. With only limited applications to dentistry, mainly in cleft work, the trials gave a stimulating but accessible account of the biology, science, medicine and business behind the work to prevent scarring. The technology is based on the role of growth factors in wound healing, but the protocols for three phases of trials are highly demanding, and correspondingly expensive. If the preparations are applied at the time of surgery, or within twelve hours of trauma or burns, the prospect of scar-free wound healing is approaching reality. For reduced iatrogenic damage in eye and brain surgery particularly, facial burns, ligament injuries, cleft lip and palate repairs, the benefits would be enormous. Extensive animal experimentation was essential in earlier stages, said the speaker, who also described the work on the first human volunteer, himself. These hard decisions, risks and years of investment all merit support from the wider scientific community of which the dental profession is proud to be a part. Only after the next stage, Phase 3 trials, will the products be licenced for sale. Watch for the flotation in three years!

The science of ozone, and its applications to dentistry, were the subject of great speculation and interest in the coffee queues. KaVo was showing the equipment on their stand and sponsored a fringe presentation by Professor Edward Lynch of Queen's University, Belfast in addition to his scheduled talk in the main programme. The application of ozone to carious lesions is said to kill virtually all bacteria and allow remineralisation. The company promised that twenty practitioners could be special-price purchasers in return for providing feedback on their results. The prospect of "profits exceeding $£ 10,000$ per month from the technique" were held out. The non-invasive treatment of caries is the

\section{IT'S A FACT!}

* A total of 1,940 delegates attended the conference.

* There were 81 exhibition stands in total.

* The most popular session was 'Quality Restorative Dentistry' on Friday 3 May when 713 people attended.

* There were 117 young BDA/IDA members -49 more than last year.

Holy Grail of dentistry, but the contrast between this approach to the market and that of the Renovo group was striking. Even more speculative is the idea that ozone's undoubted bactericidal properties could be used in ointments and other topical and prophylactic applications. Dr Thomas Daly gave out samples to introduce delegates informally to a product he has used to prevent dry sockets and treat other conditions. I can only say that it cleared up a longstanding angular cheilitis in a few hours on a human volunteer. You read it here first!

Was this the year of the singing Scandinavians? Dr Sverker Toreskog kept his audience amused with the occasional serenade during his lecture on bonded porcelain. And it is reported that 'amazing scenes were witnessed' at the black tie dinner when a tired and emotional Swede launched into song, possibly goaded by the wearisomely over-running official speeches. Is time running out on these formal social events? Does the changing demography of the profession demand a rethink?

'From wear to vomiting' was the remit of Sverker Toreskog's contribution on uses of minimally invasive bonded porcelains. A clinician with 42 years of experience made more valuable by his detailed records and photographs, he was persuasive about what works in these difficult cases. Looking though his 100,000 slides has given him a unique insight into the aesthetic failures of various techniques. It says something for his surgery management skills that while he has got through three wives he still has the same dental nurse! He advocated staying away from gingival margins to avoid damage and bleeding and making thin but extensive coverage preparations. He asserted that dental personnel ask for these rather than PFM crowns. His mantra was 'stay in enamel', his concern was for good bonding and avoiding damage to the pulp. If 50 $60 \%$ of subgingival finishing lines are exposed within 5 years, the supragingival margin is superior. It can be made virtually invisible by using thin section porcelains, good cementation techniques and the best bonding materials for enamel. Dentine bonding is still a problem, according to $\mathrm{Dr}$ 
Toreskog and those who heard his critique of composite restorations and their marginal breakdown will have taken away the notion of 'compos**t'.

What distinguishes a workshop from a lecture session? In the case of the 'TraumaSolving Practical Problems' session, not a lot. Detailed repetition of the implications of open and closed apices, splinting protocols, and permutations of clinical features and possible treatments and outcomes were overwhelming in their coverage of the topic. Handouts might have helped attendees retain some of this mass of information. There were few questions, although the interest level was raised by $\mathrm{Dr}$ Peter Mullen, an Ulster practitioner, who advocated his system of being on-call to his local A \& E department for trauma cases and thereby building experience and goodwill. Dr June Barrell, Edinburgh, rated the speakers highly and felt that the information on the timing of treatments was very helpful. Programme makers must of course build in a balance between basic information and the more esoteric and leading-edge topics. If you knew nothing about trauma, then this was the session for you.

Management, marketing and other non-clinical subjects have achieved increasing prominence in the programme after decades in which these topics were beyond the pale. Work-life balance, leadership, teams, nurse-dentist communication, audit using IT, and aspects of private practice all featured. It is a sign of the distancing of practitioners from the NHS that the word 'conversion' is now instantly understood to be about private practice, not religion. With a large number of young and VDP delegates at the conference the motion at the well-attended debate, "Associates are parasites and bleed practices dry", was never going to be popular. Property prices and debt levels on graduation mean that early earning power is crucial and agreements of less than $50 \%$ gross

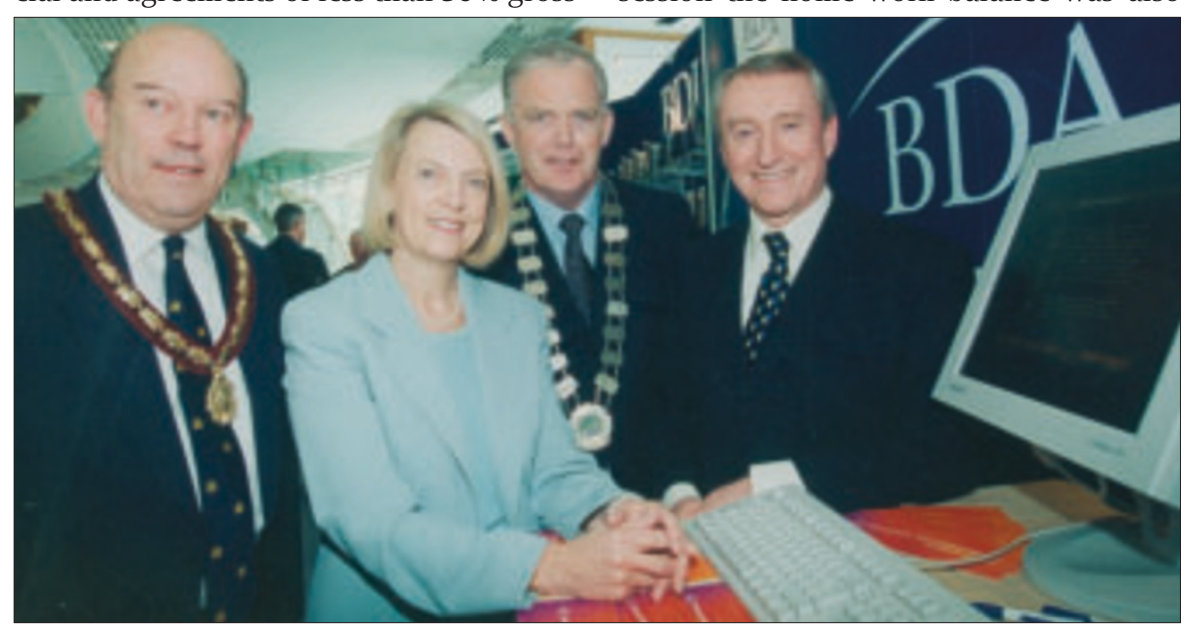

Pictured above checking out the BDA web are (from left to right) former BDA President Peter Swiss, Doreen Wilson CDO of Northern Ireland, Joe O'Byrne the President of the Irish Dental Association and Mr Clive Gowdy Department of Health, Social Services \& Public Safety's Permanent Secretary. fees may be unattractive to associates. The disincentives for buying a partnership when earnings are greater and responsibilities are fewer as an associate were aired. This in effect reinforces the actuarial view that associates are disproportionately costly for principals. There was a suspicion that a principal might not be pleased when patients expressed a preference for the associate! Dr Hew Mathewson said that even with a sliding scale and NHS patients there was no difficulty in attracting associates to a good, well-run practice.

As always Dr Joe Mee was well received, talking about the reasons dentists needed help combating drug and alcohol addiction. It is a truism that giving information does not change behaviour, but knowing that cannabis is now stronger and more addictive than previously and stays in body fat cells longer may give recreational users within the profession a reason to rethink. In this 'young dentists' session the home-work balance was also

\section{WINNERS OF BDA AWARDS}

Announcements

President Ian Benington

Vice President Geoffrey Garnett

\section{Fellowship}

Philip Jenkins

John Tomes Medal

Stanley Gelbier

Roll of distinction

John Bulman and Tony Hudson

Life membership

David Baird, Sherwood Hobson and R Wallace Glass

Dentists Provident Society/BDA Student Elective Awards 2001

Rachel Walker (Elective Protocol Winner) and Alison Hutton (Elective Report Winner)

Glaxo SmithKline/BDA Tooth Wear/Dental Erosion Research Grant 2001 Brenda Murray

The Wrigley Oral Health Care in Action Dental Student Award 2002 (in association with the BDA)

Esma Dogramaci

BDA Research Foundation and Shirley Glasstone Hughes Memorial Prize 2001 Colin Alexander Murray and Miranda Pring

explored. To assert as one speaker did, that home should be play time ignores the reality of many, especially the increasing numbers of women dentists, who find home and family cares equally demanding. Sometimes going to work is the easy bit!

The session "Quality Assurance in General Dental Practice" looked at several systems of monitoring and managing treatment. Speakers from the floor reported that measuring Denplan patients sixmonthly was a success at first, but patients then got bored. Dr Gordon Hunter, second generation dentist in Ayr and doing an MBA in Healthcare Management, had mixed feelings about the use of the Oral Health Score in practice. It summarised and superseded previous lengthy models, but was still impracticable on NHS fees. "And the NHS is part of the culture in Scotland", he said. He regarded the BDA's 'Good Practice' scheme as the market leader in the field of practice audits although he criticised the absence of business results in it. Most riveting was the assured, smart and humorous presentation by Dr Max Anderson from Delta Dental Plan in Seattle that healthcare management system for 1.6 million people has used its data banks to look at outcomes of treatment and influence them for the better. The plan was changed to allow more frequent scaling and root planning for periodontal patients and the predicted result, less need for painful and expensive surgical treatment, was achieved. They use sealants on 7 to 13 year olds extensively because most disease in this age group is in unsealed molars. Cuspal coverage of rootfilled teeth is encouraged as this gives a four-fold increase in survival. Nice to hear about a system that encourages and 


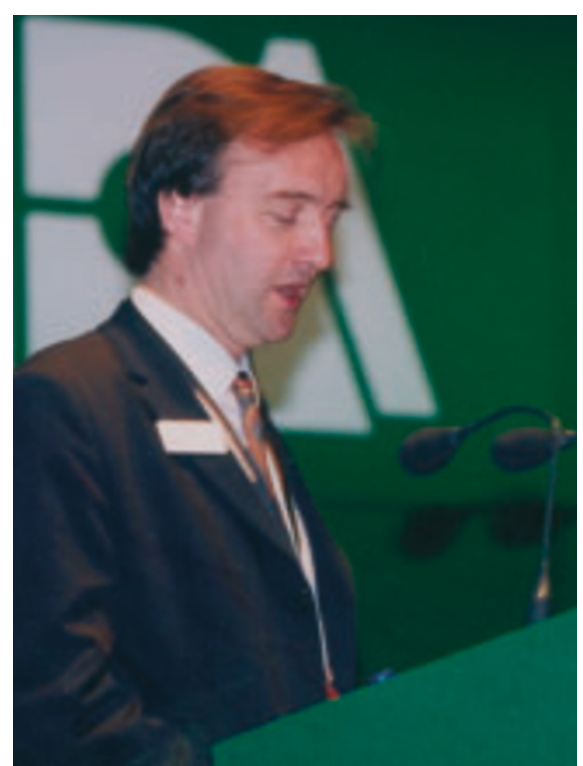

BDA Chief Executive lan Wylie speaking at conference.

rewards good dentistry.

Dr Anderson's statistics showed that $10 \%$ of his patient population got $98 \%$ of the periodontal treatment. Although his is a non-random sample it suggests that smoking levels in Seattle insurees are low. Dr Brian Mullally, a Belfast consultant, took a wide-ranging look at the effect of smoking on oral health. He emphasised the need to use youth oriented programmes to prevent addiction taking a hold before the age of 21. It was good to hear that a dentist, John Burdell DDS, recognised the association between smoking and gum disease back in 1849.

What makes a good team leader? Research done for local government and the NHS was the basis for Sheila Scott's presentation. Evidence-based advice in the business and management field is reassuringly taking over from the guru approach. The top five characteristics identified are all 'people skills' and don't include charisma or intelligent, analytical thinking, although these feature lower down the list.
The first essentials are to have a genuine concern for others; to be an inspirational communicator and achiever; to empower others; to work with transparency and integrity; and to be accessible, approachable and flexible. It is also important to be decisive, determined and willing to take risks, and to be an intelligent, creative thinker who supports a development culture. Challenging and fulfilling roles which the young graduates shying away from partnerships might consider when making career choices.

Another standing-room-only workshop was that given by Professor Ruth Freeman for Women in Dentistry's Lunch and Learn, attended by both the Northern Ireland and England and Wales CDOs. Her research looked at the different perceptions of the dentist-nurse working relationship between the two genders. Not surprisingly she found that men flirt with their nurses and prefer them to be female, whilst maintaining a business-like relationship, whereas women shared experiences and had a more interpersonal, friendly style with them. This was a workshop in which the discussion and questions from men and women, young and older practitioners, contributed fully to the topic. Looking at age differences it was felt that younger women dentists needed help in establishing a balance between the business and friendship aspects of working relationships. Some VDPs present described difficulties they'd had, "all of us had problems with our nurses at first, some even had to change their nurse". The speaker emphasised the need for nurses to feel appreciated and involved in the dentistry. A woman with experience of working with male nurses recounted her surprise at how much larger they were! Dr Jackie Sowerbutts, Surrey, summed up by saying that the research indicated a need to develop leadership styles for young women dentists. Back to Sheila Scott's advice!

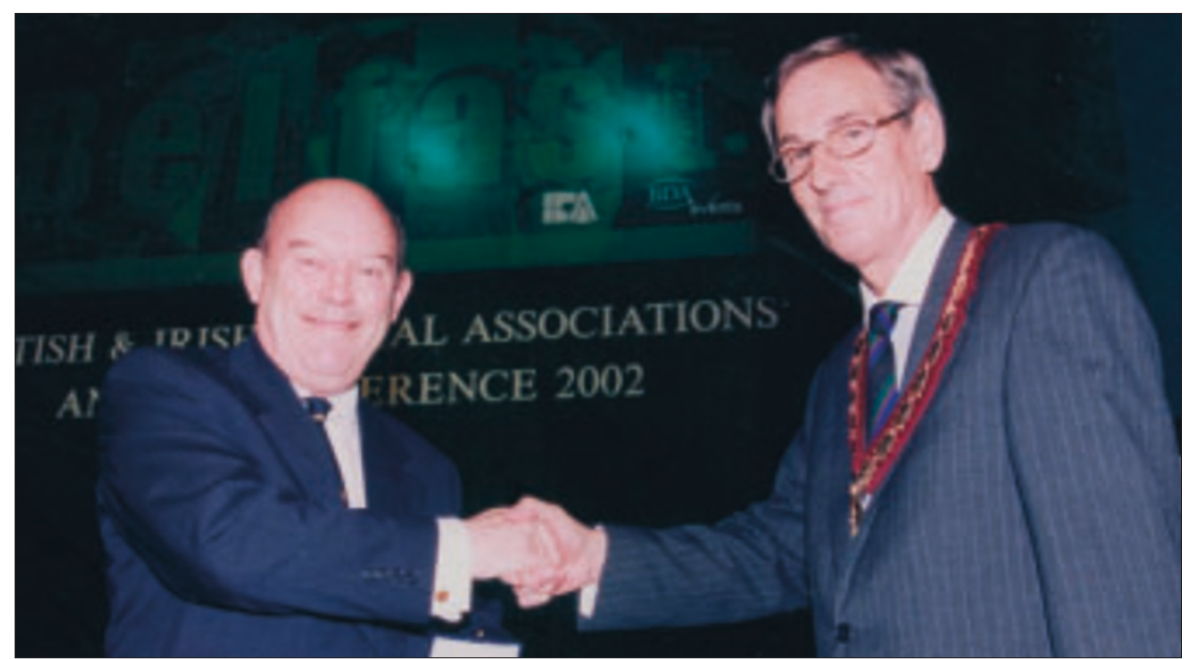

Peter Swiss is congratulated by lan Benington (top right) who presents him with his past president's badge at the ceremony.

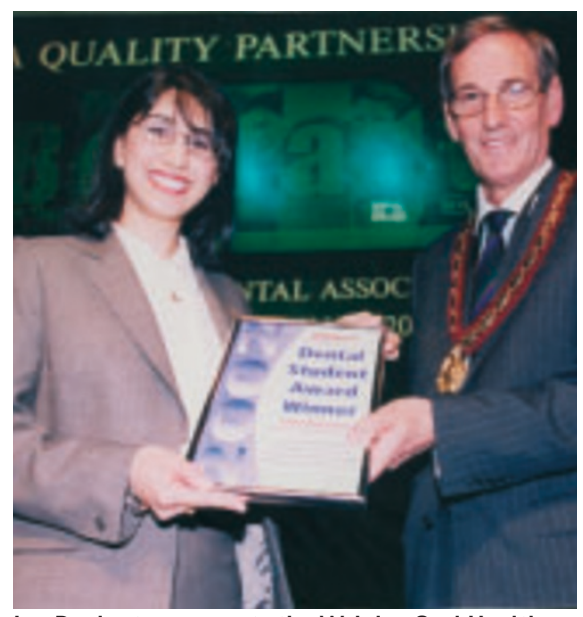

lan Benington presents the Wrigley Oral Health Care in Action Dental Student Award 2002 (in association with the BDA) to Esma Dogramaci.

Outgoing President Peter Swiss expressed pleasure at the good level of attendance, despite it being a longer trip for most delegates. Registration officials must be congratulated for some good lateral thinking on admitting a career-break dentist at the cheaper auxiliary rate. Incoming President, Professor Ian Benington, confessed he'd worn his trouser knees out, praying for good weather. He obviously has a direct line to somewhere, and the sun shone out of brilliant blue skies every day. The Waterfront Hall was well situated and had good auditoria, but space for the trade was cramped or hidden away and it was hard to find a lunch. Bar code technology enabled those in need of CPD credits to 'register early and register often'. A wonderful slide montage of scenes from countries with participating speakers had been produced for Northern Ireland's CDO Doreen Wilson and was accompanied by an equalling enchanting musical backing. Dutiful attendees kept the statutory AGM of the BDA quorate, but it resembled a shareholders' meeting before that species started getting difficult. The feeling overall was that the event had been relaxed, informative and enjoyable. Next year in Manchester (24-26 April 2003) attendance should be even higher and the programme promises to be even more varied. Be there!

Sponsors of the event included:

ADEC

BDA Northern Ireland Branch

BDA UDT \& RW Group

Colgate

Denplan Ltd

Dental Protection Lto

Dentists' Provident Society

GlaxoSmithKline

Nobel Biocare Ltd

Wrigley Oral Healthcare in Action 